\title{
The impact of age and gut microbiota on Th17 and Tfh cells in K/BxN autoimmune arthritis
}

Fei Teng ${ }^{1}$, Krysta M. Felix ${ }^{1}$, C. Pierce Bradley ${ }^{1}$, Debdut Naskar ${ }^{1}$, Heqing Ma', Walid A. Raslan and Hsin-Jung Joyce $\mathrm{Wu}^{1,2^{*}}$

\begin{abstract}
Background: Age is an important risk factor for rheumatoid arthritis (RA), which often develops in middle age. However, how age-associated changes in immunity impact RA is poorly understood. Gut microbiota are known to be involved in the pathogenesis of RA, but the effects of microbiota in older subjects remain mostly unknown.

Methods: We used segmented filamentous bacteria (SFB), a gut commensal species with immunomodulatory effects, and K/BxN mice, a T cell receptor (TCR) transgenic model, to study the effect of age and microbiota on autoimmune arthritis. Comparing young and middle-aged K/BxN T cells of the same TCR specificity allows us to study T cells with an age focus eliminating a key variable: TCR repertoire alteration with age. In addition to joints, we also studied pathological changes in the lung, an important extra-articular RA manifestation. We used flow cytometry to evaluate $T$ follicular helper (Tfh) and Thelper 17 (Th17) cells, as they both contribute to autoantibody production, a key disease index in both RA and K/BxN arthritis.

Results: Middle-aged K/BxN mice had aggravated arthritis and pathological changes in the lung compared to young mice. Middle-aged mice displayed a strong accumulation of Tfh but not Th17 cells, and had defective Th17 differentiation and low expression of interleukin-23, a critical cytokine for Th17 maintenance. Although a soaring Tfh cell population accompanied by robust germinal center B cell responses were found in middle-aged mice, there was decreased cycling of Tfh cells, and SFB only induced the non-Tfh cells to upregulate Bcl-6, the Tfh master transcription factor, in the young but not the middle-aged group. Finally, the accumulated Tfh cells in middle-aged mice had an effector phenotype (CD62L $\left.{ }^{\text {lo }} \mathrm{CD} 44^{\text {hi }}\right)$.

Conclusion: Age-dependent Tfh cell accumulation may play a crucial role in the increased autoimmune disease phenotype in middle-age. SFB, a potent stimulus for inducing Tfh differentiation, fails to promote Tfh differentiation in middle-aged K/BxN mice, suggesting that most of the middle-aged Th cells with an effector phenotype are Tfh effector memory cells induced at an earlier age. Our results also indicate that exposure to immunomodulatory commensals may allow the young host to develop an overactive immune system reminiscent of that found in the middle-aged host.
\end{abstract}

Keywords: Rheumatoid arthritis, Age, Gut microbiota, Th, Th17, Animal model, Lung pathology

\footnotetext{
* Correspondence: joycewu@email.arizona.edu

'Department of Immunobiology, University of Arizona, Tucson, AZ 85719,

USA

${ }^{2}$ Arizona Arthritis Center, College of Medicine, University of Arizona, Tucson,

AZ 85719, USA
} 


\section{Background}

Age-related reductions in immune functions in vaccination, infection, and cancer have been better characterized [1]; however, little is known regarding the ageassociated changes in immune function that result in autoimmunity. This is a pivotal field that warrants a strong research focus as there is a clear association between age and increased incidence of many autoimmune diseases including rheumatoid arthritis (RA), myositis, and Sjögren's syndrome [2]. RA onset can occur at any age, but it usually develops in middle-aged adults between 40 and 60 years old [3]. Recently, gut microbiota have been demonstrated to have a profound influence on host health and disease [4-7]. Reports have found that microbiota in older people are different from those in younger adults $[8,9]$. We and others have demonstrated that gut microbiota can act as an environmental cue to induce autoimmune arthritis in both humans and mice [10-13]. However, a causative effect of microbiota in age-related disease development among older individuals remains to be determined.

Here, we aimed to investigate the age-associated and microbiota-associated impacts on autoimmune disease. Because RA is an autoantibody-mediated autoimmune disease $[14,15]$, we are interested in two crucial subsets of effector $\mathrm{T}$ cells that provide help to B cells for autoantibody production. $\mathrm{T}$ follicular helper ( $\mathrm{Tfh}$ ) cells are a crucial subset of $\mathrm{CD} 4^{+} \mathrm{T}$ cells that helps $\mathrm{B}$ cells produce high-affinity and high-titer antibodies [16-18], and an excessive Tfh cell response can lead to many autoimmune conditions including RA [19]. T helper 17 (Th17) cells, a $\mathrm{T}$ effector cell type involved in many autoimmune diseases, promote both autoantibody production and inflammation [20]. We used a TCR transgenic (Tg) autoimmune arthritis model, $\mathrm{K} / \mathrm{BxN}$ mice [21], to study the effect of age and microbiota on autoimmune Tfh and Th17 cells. K/BxN mice are an autoimmune arthritis model in which transgenic KRN T cells recognize glucose-6-phosphate isomerase (GPI), the selfantigen (Ag) presented by major histocompatibility complex $(\mathrm{MHC})$ class II I-A $\mathrm{A}^{\mathrm{g} 7}$ molecules. As in humans with RA, autoantibodies are crucial for disease pathogenesis in $\mathrm{K} / \mathrm{BxN}$ mice [21]. By examining TCR Tg $\mathrm{T}$ cells in young and middle-aged $\mathrm{K} / \mathrm{BxN}$ mice, we can compare $\mathrm{T}$ cells of the same TCR specificity with the only difference being the age of the mouse. This has been shown to be beneficial in aging $\mathrm{T}$ cell studies as it eliminates change in the $\mathrm{T}$ cell repertoire, an important variable that complicates the interpretation of aging $\mathrm{T}$ cell function [22].

In contrast to the abundant gut-luminal commensals, mucosa-associated commensal species such as segmented filamentous bacteria (SFB) represent a minor but important part of the commensal community, as they can powerfully modulate host immunity [23-27].
Our previous studies have shown that SFB-induced Tfh and Th17 cells contribute significantly to autoantibody production in young $\mathrm{K} / \mathrm{BxN}$ mice, and a lack of either $\mathrm{T}$ effector cell type strongly ameliorates autoantibody production and autoimmune arthritis development [11, 12]. Here we reveal that despite both Tfh and Th17 cells having been reported to participate in the pathogenesis of autoimmune arthritis in most of the studies using young adult mice in experimental settings, there is a clearly age-associated accumulation of Tfh but not Th17 cells in the middle-aged group compared to their young counterparts. Our results suggest that most of the accumulated middle-aged Tfh cells are of the effector phenotype. Our results further indicate that exposure to commensal bacteria SFB causes the young host to develop an overactive immune system, with a strong elevation in their Tfh cell response reminiscent of the middle-aged condition.

\section{Methods \\ Mice}

$\mathrm{K} / \mathrm{BxN}$ mice were generated by crossing KRN TCR transgenic mice on the C57BL/6 (B6) background with NOD mice (F1 mice of KRN/B6 x NOD). Ankle thickness was measured with a caliper (J15 Blet micrometer) as described previously [11]. All mice were housed at the SPF animal facility at the University of Arizona. The young mice were used at 6-8 weeks of age, while the middle-aged $\mathrm{K} / \mathrm{BxN}$ mice were used at 10-15 months of age using the age guideline of the Jackson Laboratory (Jax) described as:

Middle age refers to a phase during which senescent changes can be detected in some, but not all, biomarkers of aging. For the middle-aged group, mice should be at least 10 months old. Senescence processes that begin in younger adults (for example, collagen cross linking and accumulation of activated/memory $\mathrm{T}$ cells) often can be detected by then. The upper age limit for the middleaged group is typically 14-15 months, because at this age, most biomarkers still have not changed to their full extent, and some have not yet started changing.

All experiments were conducted according to the guidelines of the Institutional Animal Care and Use Committee at the University of Arizona under the protocol reference number 11-278.

\section{Preparation of single-cell suspension from the lung and small intestine-lamina propria (SI-LP)}

Lungs were perfused with $10 \mathrm{ml}$ PBS to remove blood, and were finely minced. Minced lung was placed into $10 \mathrm{ml}$ of digestion buffer containing $1 \mathrm{mg} / \mathrm{ml}$ each of Collagenase D (Roche) and $\mathrm{MgCl}_{2}$ and $0.15 \mathrm{mg} / \mathrm{ml}$ DNase I (Sigma) in DMEM (HyClone). Lungs were digested for $20-25 \mathrm{~min}$ at $37^{\circ} \mathrm{C}$ at $200 \mathrm{rpm}$ then passed 
through a $100-\mu \mathrm{m}$ cell strainer. A plunger from a $5-\mathrm{ml}$ syringe was then used to grind remaining tissue pieces through the cell strainer. SI-LP cells were isolated as described, with some modification [11]. Briefly, Peyer's patches (PPs) were removed from the small intestine. The small intestine was opened longitudinally and excess mucus was removed by scraping gently with forceps along the length of the intestine. The intestine was then thoroughly washed in $5 \mathrm{mM}$ ice-cold ethylenediaminetetraacetic acid (EDTA) in PBS and cut into 1-cm pieces, which were incubated in $40 \mathrm{ml}$ of $5 \mathrm{mM}$ EDTA and $0.145 \mathrm{mg} / \mathrm{ml}$ of DL-dithiothreitol (DTT) in DMEM for $60 \mathrm{~min}$ at $37{ }^{\circ} \mathrm{C}$ horizontally at a rotation speed of $100 \mathrm{rpm}$. After incubation, the epithelial cell layer, containing the intraepithelial lymphocytes, was removed by shaking, and then cleaned by pressing intestinal pieces over a $100-\mu \mathrm{m}$ nylon layer on top of a paper towel. Intestinal pieces were then transferred to an eppendorf tube with $600 \mu \mathrm{l}$ of digestion solution containing $1 \mathrm{mg} /$ $\mathrm{ml}$ Collagenase D (Roche), $0.15 \mathrm{mg} / \mathrm{ml}$ DNase I (Sigma), and $200 \mathrm{ng} / \mathrm{ml}$ liberase $\mathrm{Cl}$ (Roche). The pieces of intestine were finely minced and transferred to a $50-\mathrm{ml}$ conical tube containing $5 \mathrm{ml}$ of digestion solution. Digestion was performed by incubating the pieces at $37{ }^{\circ} \mathrm{C}$ for $15 \mathrm{~min}$ with rotation at $200 \mathrm{rpm}$. After digestion, $10 \mathrm{ml}$ EDTA/PBS was added and the solution was passed first through a $100-\mu \mathrm{m}$ cell strainer, then through a $40-\mu \mathrm{m}$ cell strainer. Cells were centrifuged and washed again with EDTA/PBS before being resuspended in 10\% FBS DMEM for stimulation.

\section{Antibodies and flow cytometry}

For surface staining, fluorophore-conjugated monoclonal antibodies (mAbs) specific for CD4 (RM4-5), CD19 (6D5), CD45 (30-F11), PD-1 (RMP1-30), CD11b (M1/70), CD44 (IM7), CD62L (MEL-14), and TCR $\beta$ (H57-597) were obtained from BioLegend. Abs recognizing Fas (Jo2), CXCR5 (2G8), and TCR VB14 (14-2) were from BD Pharmingen. Anti TCR V $\beta 6$ (RR4-7) was from eBioscience. FITCconjugated peanut agglutinin (PNA) was from Vector Laboratories. For intracellular cytokine staining, cells were incubated for $4 \mathrm{~h}$ with BD GolgiPlug (1:1000 dilution), $50 \mathrm{ng} / \mathrm{ml}$ phorbol 12 -myristate 13 -acetate, and $1 \mu \mathrm{M}$ ionomycin in DMEM (HyClone) supplemented with 10\% FCS, $1 \%$ nonessential amino acids, penicillin, streptomycin, and glutamine at $37{ }^{\circ} \mathrm{C}$. Intracellular cytokine staining was performed with Cytofix/Cytoperm (BD Pharmingen). Abs recognizing interleukin-17A (IL-17A, TC11-18H10.1) were obtained from BioLegend and Abs recognizing IL-23 (fc23cpg) were obtained from eBioscience. For intranuclear staining, buffers from a Foxp3 Staining Buffer Set (eBioscience) were used to stain Abs recognizing Ki-67 (B56, eBioscience) and Bcl-6 (K112-91, BD Pharmingen).
Cells were run on an LSRII (BD Biosciences), and analyses were performed using FlowJo (TreeStar) software.

\section{Microbiota reconstitution and quantification}

Our SPF mouse colony and SFB colonization were maintained as described previously [12]. Briefly, our SPF mouse colony was originally derived from Jax and was verified as SFB-negative (SFB- hereafter). SFB were initially introduced to our mouse colony by gavaging mice with feces containing SFB, from Taconic B6 mice. Later, SFB were passed by gavaging mice with feces containing $\mathrm{SFB}$, collected from the SFB+ mice housed in our colony. SFB- mice were weaned at 21 days old and rested for 1 day. Then, mice were orally gavaged with feces containing SFB, collected in-house for 3 consecutive days starting at 23 days old. The middle-aged $\mathrm{K} / \mathrm{BxN}$ mice aged 10-15 months were gavaged at the same time as the young mice. The SFB- mice were the un-gavaged littermate controls. Unless otherwise mentioned, the SFB colonization status was examined on day 10 after SFB gavage by SFB-specific $16 \mathrm{~S}$ rRNA quantitative PCR as previously described [11].

\section{ELISA}

Anti-GPI Ab titers were measured as described [11]. Briefly, ELISA plates were coated with recombinant mouse GPI at $5 \mu \mathrm{g} / \mathrm{ml}$, and diluted mouse serum was added. Subsequently, plates were washed and alkalinephosphatase (AP)-conjugated anti-mouse IgG $\mathrm{Ab}$ was added. After the final wash, AP substrate was added and titers were quantified as optical density values using an ELISA reader. The Ab titers were expressed as arbitrary units, which were calculated from serial dilutions of sample serum and defined as the reciprocal of the highest dilution that gave a background optical density (OD) value set as 0.15 .

\section{In vitro Th17 polarization}

Splenic naive $\mathrm{CD} 4^{+} \mathrm{T}$ cells $\left(2.5 \times 10^{4}\right)$ from SFB young or middle-aged $\mathrm{K} / \mathrm{BxN}$ mice were enriched by fluorescenceactivated cell sorting (FACS Aria) and in vitro cultured in 96-well plates for 4 days in Th17 polarization conditions: anti-CD3 $\varepsilon$ (plate-coated, $2 \mu \mathrm{g} / \mathrm{ml})$, anti-CD28 $(2 \mu \mathrm{g} / \mathrm{ml})$, anti-IL-2 (10 $\mu \mathrm{g} / \mathrm{ml}$, JES6-1A12, BioXCell), IL-6 (50 ng/ $\mathrm{ml}$, PeproTech), transforming growth factor (TGF) $\beta 1$ (1 ng/ml, PeproTech), 6-formylindolo [3,2-b] carbazole (FICZ), (300 nM, Enzo Life Sciences).

\section{Immunohistochemical analysis}

Lung sections from SFB- and $\mathrm{SFB}+\mathrm{K} / \mathrm{BxN}$ mice were perfused and fixed with $10 \%$ (vol/vol) buffered formalin and stained with hematoxylin and eosin (H\&E) for histological evaluation of lymphocyte aggregation. Image 
analysis was performed using Image J software $(\mathrm{NIH}$, Bethesda, MD, USA).

\section{Statistical analysis}

Differences were considered significant with $p<0.05$ analyzed by Student's $t$ test (two-tailed, unpaired) or twoway analysis of variance (ANOVA) (Prism 6, Graph-Pad Software), with significance level denoted as: ${ }^{*} p<0.05$, ${ }^{* * *} p<0.01,{ }^{* * * *} p<0.001$, and ${ }^{* * * * *} p<0.0001$. We also used Prism to calculate Spearman correlation.

\section{Results}

The impact of age and gut microbiota on RA-related autoimmune arthritis and pathological changes in the lung Autoantibodies are a hallmark of B-cell-mediated autoimmune diseases, including RA. As in patients with RA, serum autoantibodies serve as the disease index in the $\mathrm{K} / \mathrm{BxN}$ model and indeed, passive transfer of $\mathrm{K} / \mathrm{BxN}$ arthritic serum (containing anti-GPI autoantibodies) into wild-type mice is sufficient to induce arthritis development [21]. Thus, to examine the effects of microbiota and age on autoimmune arthritis development, we first compared the ankle thickness and anti-GPI autoantibody titers between young and middle-aged $\mathrm{K} / \mathrm{BxN}$ mice. As reported previously, SFB colonization significantly enhanced arthritis development in the control young K/ $\mathrm{BxN}$ mice as indicated by the increase in ankle thickness (Fig. 1a). The majority $(\sim 65 \%)$ of SFB- mice developed arthritis (ankle thickness $>3 \mathrm{~mm}$ ) at a young age, $\sim 6$ weeks old, and the rest $(\sim 35 \%)$ developed arthritis between 6 weeks and 10 months, by middle age. This is in contrast to the SFB+ group, in which all mice developed arthritis at a young age. This disease phenotype corresponded with an increase in anti-GPI autoantibody titers (Fig. 1b). In the middle-aged group, severe arthritis had already been observed in SFB- mice, and SFB colonization did not further augment arthritis severity (Fig. 1a) and only mildly increased the anti-GPI titers (Fig. 1b). Overall, we found that middle-aged $\mathrm{K} / \mathrm{BxN}$ mice displayed greater ankle thickness and anti-GPI titers compared to their young counterparts.

Next, we examined whether there was a correlation between anti-GPI titer and ankle thickness in $\mathrm{K} / \mathrm{BxN}$ mice. Specifically, we pooled all mice from three independent experiments for which we have recorded data containing ankle thickness for each mouse and its corresponding anti-GPI titer, and used Prism to compute the $p$ value for nonparametric (Spearman) correlation. Our data indicate there is significant and strong correlation between autoantibody titer and ankle thickness (Fig. 1c). Inducible bronchus-associated lymphoid tissue (iBALT) is a type of ectopic lymphoid tissue found in the lungs of patients with RA and is positively correlated with the severity of the patient's lung disease [28]. Previously we have demonstrated that SFB colonization provoked young $\mathrm{K} / \mathrm{BxN}$ mice to develop iBALT-like structures closely resembling the iBALT formations in patients with RA $[29,30]$. Here, we compared iBALT lesions between young and middle-aged groups with or without SFB colonization. SFB induced iBALT areas in young $\mathrm{K} / \mathrm{BxN}$ mice. In contrast, middle-aged $\mathrm{K} / \mathrm{BxN}$ mice displayed strong iBALT lesions compared to young mice regardless of SFB status (Fig. 1d). Next, we evaluated the ability of SFB to colonize young and middle-aged $\mathrm{K} / \mathrm{BxN}$ mice and found that SFB was able to colonize and persist in middle-aged hosts at a higher level than in young hosts at several time points (Fig. 1e). However, the difference between the middle-aged and young groups seemed to subside by day 49 after gavage.

\section{SFB-induced Th17 response is impaired in the middle-aged group}

Because Th17 cells have been reported to be involved in the pathogenesis of autoimmune diseases, including in the $\mathrm{K} / \mathrm{BxN}$ model, we first compared whether there is an elevated number of Th17 cells in the spleen of middle-aged mice. In young mice, SFB is known as a strong Th17 inducer and SFB-induced Th17 cells are required for $\mathrm{K} / \mathrm{BxN}$ autoimmune arthritis development (Fig. 2a, [11, 12]). However, to our surprise, SFB colonization did not increase the splenic Th17 cell number in middle-aged $\mathrm{K} / \mathrm{BxN}$ mice. The smaller number of SFB-induced splenic Th17 cells is not due to decreased Th17 cell proliferation, as Ki-67, a cellular marker for proliferation, was expressed at a similar percentage in Th17 cells in both the young and middleaged groups regardless of SFB status. The deficiency of SFB-mediated Th17 induction in middle-aged mice was not only limited at the systemic lymphoid sites. In the lung, though SFB induced Th17 cells in middle-aged mice, the total Th17 cell numbers were severely reduced compared to their young counterparts (Fig. 2b). Th17 cells are an abundant population at steady state in gut-associated tissues, particularly the small intestinal lamina propria (SI-LP) [31]. We observed that SFB-mediated Th17 cell induction was non-existent in SI-LP in middle-aged mice. As in the spleen, we also did not observe defects in Th17 proliferation in the lung or SI-LP of middle-aged mice and the percentages of their cycling $\mathrm{Ki}^{+} 7^{+} \mathrm{Th} 17$ cells were similar to the young group (Fig. $2 \mathrm{~b}$ and c), and were relatively high compared to another $\mathrm{T}$ effector population, Tfh cells, from middle-aged mice that we examined later (Fig. 5a). Taken together, these data demonstrate that there is a defect in the middle-aged Th17 cell response to the gut microbiota SFB, though the defect is not due to a decrease in Th17 cell proliferation. 

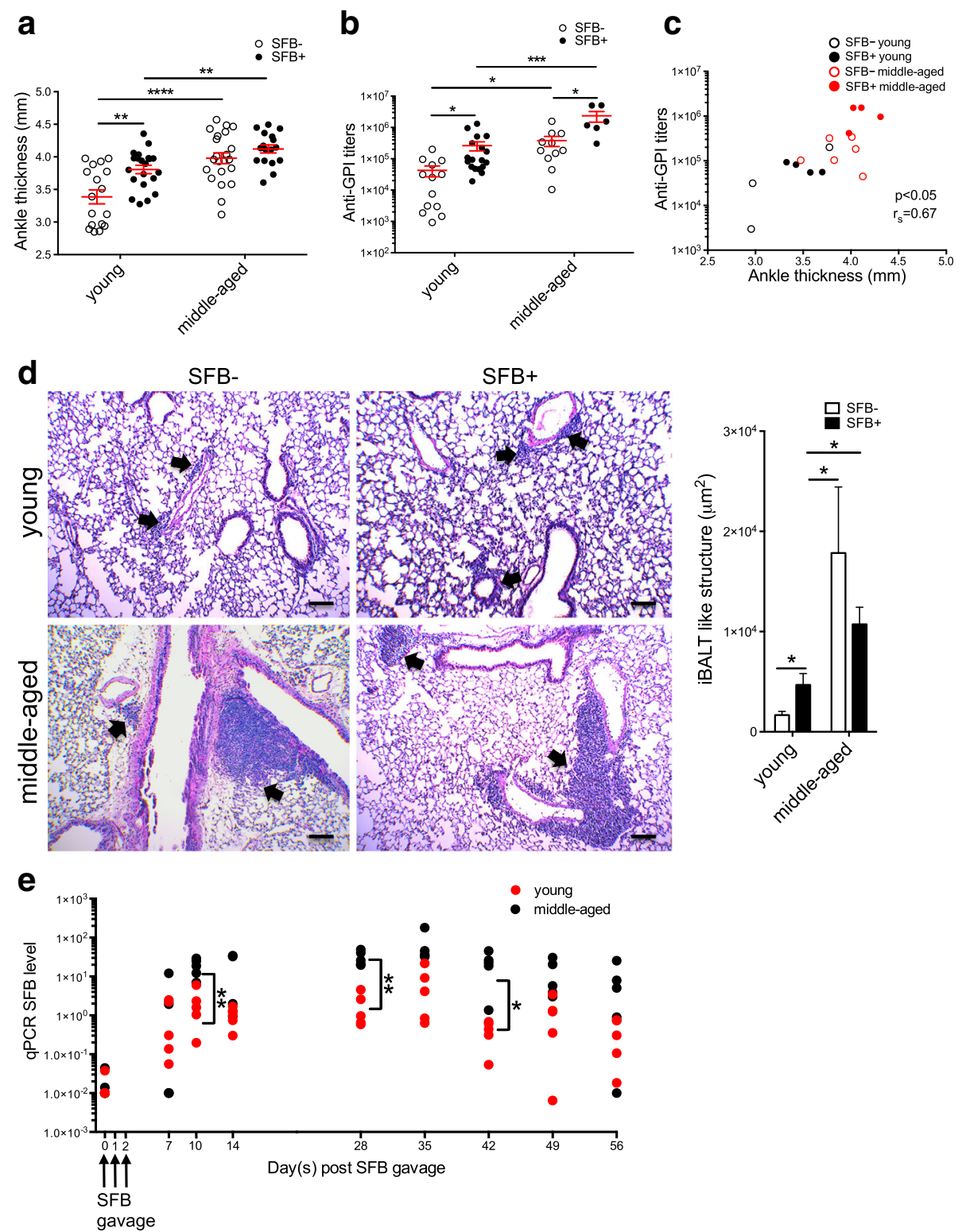

Fig. 1 Age and gut microbiota enhance rheumatoid arthritis related autoimmune arthritis and pathological changes in the lung. a K/BXN mice aged 23 days (young) or 10-15 months old (middle-aged) were gavaged for 3 consecutive days with segmented filamentous bacteria (SFB) or left non-gavaged. At 20 days after the first gavage, ankle thickness was measured and is shown as mean \pm SEM. Non-arthritic adult mice have a basal ankle thickness of $2.8-2.9 \mathrm{~mm}$ (male mice have slightly greater ankle thickness than female mice) and thus ankle thicknesses of $>3 \mathrm{~mm}$ are considered as indicative of arthritis (each dot indicates the mean value of the ankle thickness from both ankles of the same mouse). $\mathbf{b}$ Serum from young and middle-aged K/BxN mice was collected 20 days after the first SFB gavage. Anti-glucose-6-phosphate isomerase (Anti-GPI) autoantibody titers were determined by ELISA and are shown as mean \pm SEM. c Spearman correlation between anti-GPI autoantibody titers and ankle thickness in SFB- and SFB+ young or middle-aged K/BxN mice (total of 17 mice from three independent experiments). $\mathbf{d}$ Representative images of lung histologic staining (H\&E) from non-gavaged and day-20 SFB-gavaged young and middle-aged K/BXN mice. The combined and quantified data on areas of inducible bronchus-associated lymphoid tissue (iBALT)-like structures from 10 random, non-overlapped fields of each image are also shown ( $n=3-8$ mice in each group). e The SFB colonization levels of young and middle-aged K/BxN mice from the experiments as shown in a were checked at the indicated time points after SFB gavage; days indicates the number of days post first SFB gavage

\section{Middle-aged autoimmune $\mathrm{CD}^{+} \mathrm{T}$ cells are defective in Th17 differentiation}

As we did not see a defect in middle-aged Th17 cell proliferation, we next addressed whether the lower Th17 response in the middle-aged $\mathrm{K} / \mathrm{BxN}$ mice is due to a defect in Th17 differentiation. In young mice, SFB-induced Th17 differentiation requires direct recognition of SFB by an SFB-specific T-cell receptor (TCR), and dominant 


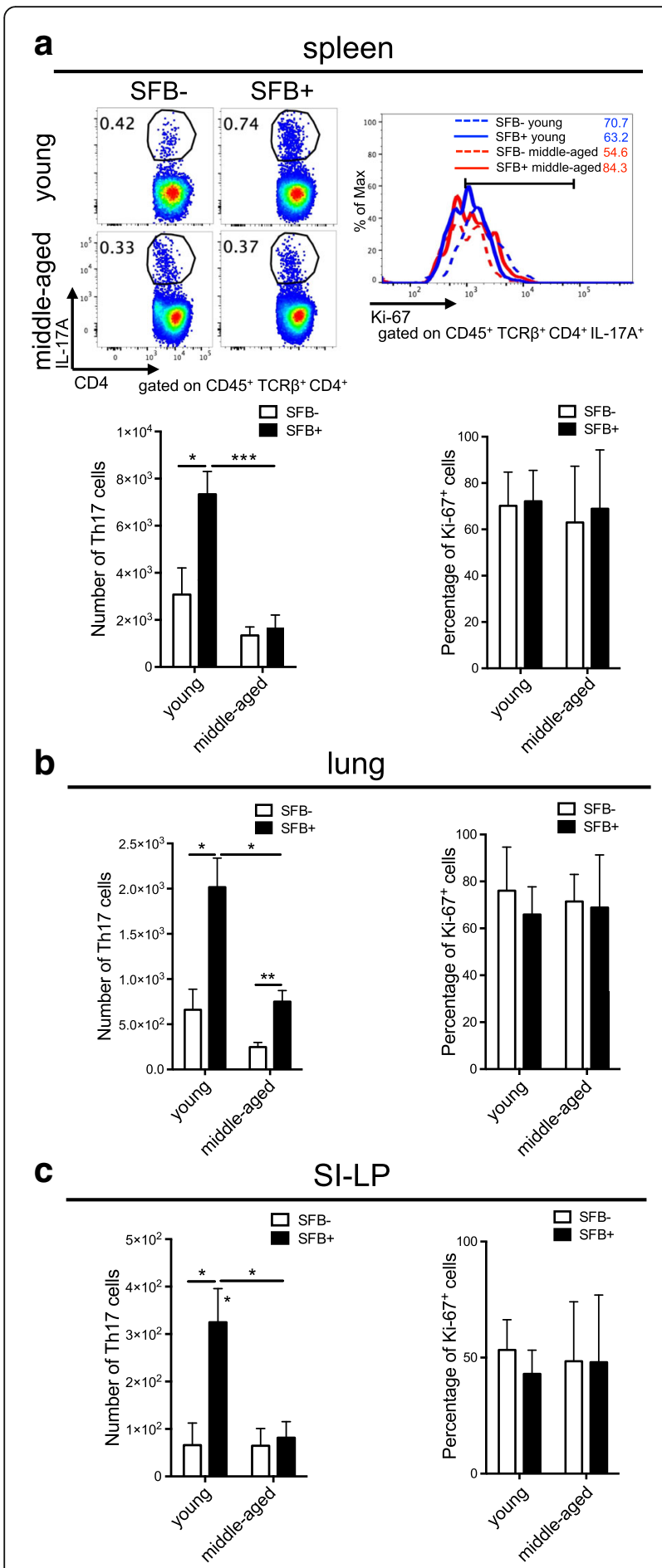

Fig. 2 Reduced SFB-mediated Th17 induction in middle-aged compared to young K/BXN mice. (a) Representative plots of Th17 cells and histogram overlays of $\mathrm{Ki}-67^{+}$Th17 cells in spleen of SFB- and SFB+ young or middle-aged $\mathrm{K} / \mathrm{BxN}$ mice are shown, along with the quantitative data of Th17 cell numbers and percentage of Ki-67 $7^{+}$Th17 cells ( $n=4-5$ mice in each group). $\mathbf{b}$ and $\mathbf{c}$. The quantitative data of Th17 cell numbers and percentage of Ki-67+ Th17 cells in lung (b) and SI-LP (c) from experiments in $2 \mathrm{~A}$ are also shown
TCR V 314 usage in the Th17 cells of young mice that recognize SFB peptide has been reported [27, 32]. Importantly, Th17 cells from middle-aged $\mathrm{K} / \mathrm{BxN}$ did display an induction of $\mathrm{V} \beta 14$ usage in their endogenous TCR V $\beta$ chain after SFB colonization in addition to the KRN TCR transgene V 36 in $\mathrm{K} / \mathrm{BxN}$ mice (Fig. 3a). We found that SFB colonization preferentially increased the population of TCRV $\beta 6^{+} \mathrm{V} \beta 14^{+}$Th17 cells by showing a skewed percentage of KRN Th17 co-expressing V $\beta 6$ and $\mathrm{V} \beta 14$ in the total TCR V $\beta 6$ (TCR V $\beta 6^{+}$expressing either $\mathrm{V} \beta 14^{+}$or $\mathrm{V} \beta 14^{-}$) population in the spleen (Fig. 3a). We also observed the skewing of Vb14 usage on KRN autoimmune Th17 cells isolated from the lung and SI-LP (Fig. 3a). This suggests that middle-aged Th17 cells were capable of upregulating the SFB-specific V $\beta 14$ TCR and the defect in SFB-induced Th17 cell response in middleaged $\mathrm{K} / \mathrm{BxN}$ mice is not due to lack of SFB exposure or recognition. We next tested whether there was an intrinsic defect in the ability of naïve $\mathrm{CD}^{+}$autoimmune $\mathrm{T}$ cells to undergo Th17 differentiation leading to the lower SFB-induced Th17 response in middle-aged mice. Naive KRN CD4 ${ }^{+} \mathrm{T}$ cells were sorted from young and middle-aged $\mathrm{K} / \mathrm{BxN}$ mice and cultured in a Th17 polarizing environment. Despite being supplied with the optimal TCR plus co-stimulus signals with Th17 polarizing cytokines, TGF- $\beta$ and IL- 6 , middle-aged autoimmune $\mathrm{CD}^{+} \mathrm{T}$ cells display an impaired ability to undergo Th17 differentiation (Fig. 3b). Thus, middle-aged CD $4^{+}$ $\mathrm{T}$ cells have an intrinsic defect in Th17 differentiation. Finally, we also examined the T cell-extrinsic molecular mechanism that may explain the low Th17 response observed in middle-aged mice, despite having $\mathrm{SFB}+$ status. When we examined a few crucial cytokines required for the development of the Th17 cell response, we found that there was decreased expression of IL-23, a critical cytokine for the maintenance of Th17 cells [33], in $\mathrm{CD}_{11} \mathrm{~b}^{+}$cells from $\mathrm{SFB}+$ middle-aged mice compared to $\mathrm{SFB}+$ young mice (Fig. 3c). Together, these data provide both T-cell-intrinsic and T-cell-extrinsic mechanisms explaining the Th17 defect in middle-aged $\mathrm{K} / \mathrm{BxN}$ mice.

\section{A robust Tfh cell response leads to a strong germinal} center (GC) B cell development in middle-aged $\mathrm{K} / \mathrm{BxN}$ mice We next examined Tfh cells, a key cell type involved in Ab-mediated autoimmune diseases. We compared the Tfh cell response between young and middle-aged groups in the spleen, which is a systemic lymphoid tissue and the major autoantibody production site corresponding to arthritis development [34]. SFB colonization induced a Tfh cell (defined by $\mathrm{PD}-1^{+} \mathrm{CXCR} 5^{+}$) response in young $\mathrm{K} / \mathrm{BxN}$ mice as we have reported previously (Fig. 4a, [12]). The Tfh cell response increased robustly in the middle-aged compared to the young group regardless of SFB status. Tfh cells are the key cell type 

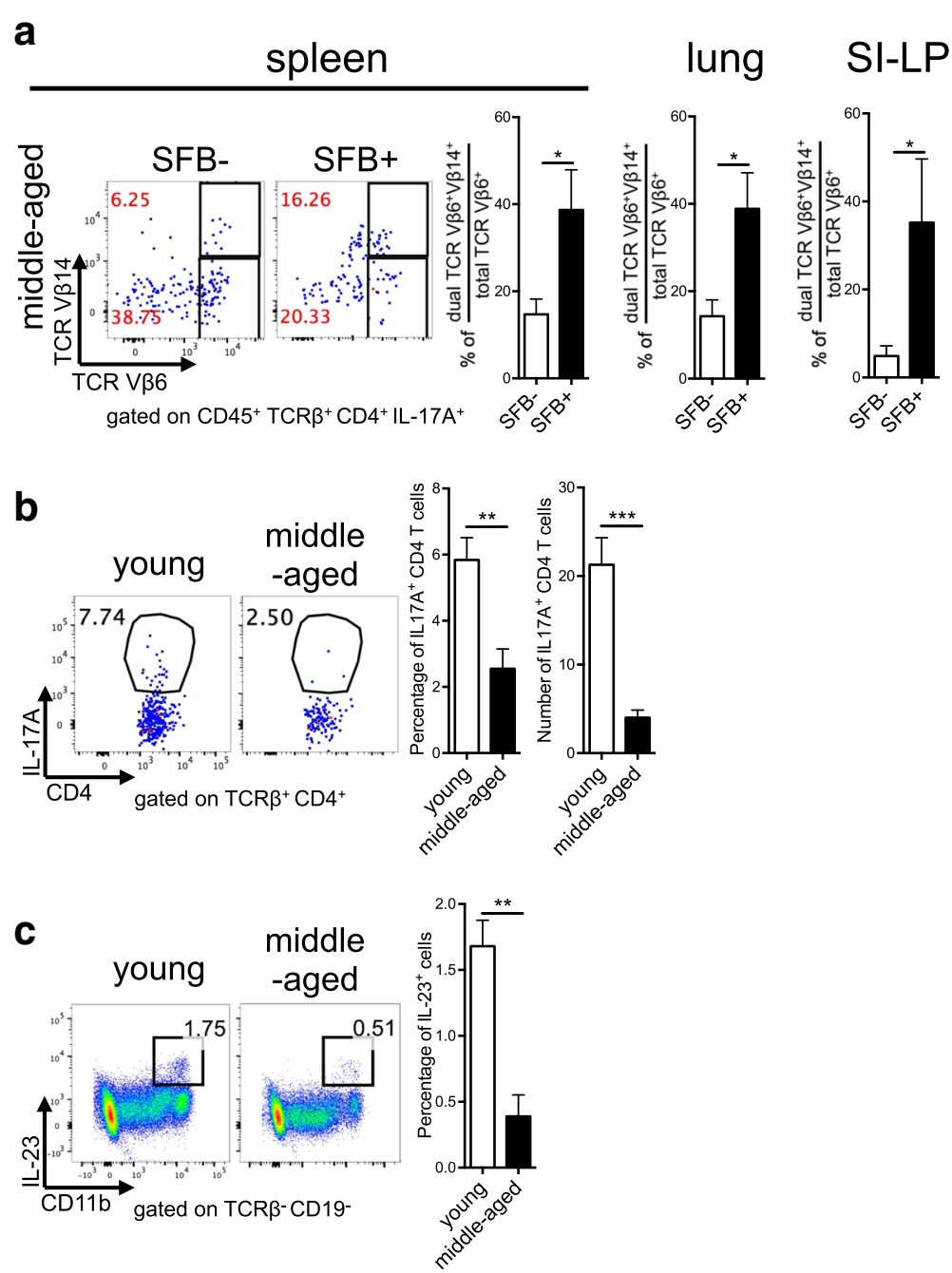

Fig. 3 Middle-aged naïve T cells display impaired T helper 17 (Th17) cell differentiation. a Representative plots of T cell receptor (TCR) VB6 vs. TCR V 114 expression in splenic Th17 cells from segmented filamentous bacteria-negative (SFB-) and SFB+ middle-aged K/BxN mice. The quantitative data show the percentage of skewed $\mathrm{V} \beta 14^{+} \mathrm{V} \beta 6^{+}$usage are calculated by $100 \times\left[\mathrm{V} \beta 6^{+} \mathrm{V} \beta 14^{+}\right.$Th17 cell percentage /total (both $\mathrm{V} \beta 14^{-}$and $\mathrm{V} \beta 14^{+}$) TCR VB6 ${ }^{+}$Th17 cell percentage]. The quantitative data on TCR skewing in the lung and small intestine-lamina propria (SI-LP) are also shown $(n=$ 3-6 mice in each group). b Fluorescence-activated cell-sorted splenic naïve CD4 ${ }^{+} \mathrm{T}$ cells from SFB- young and middle-aged K/BxN mice were in vitro cultured under Th17 polarization conditions for 4 days. Representative plots and quantitative data on Th17 polarization are shown ( $n=4-7$ mice in each group). $\mathbf{c}$ Representative plots and quantitative data on IL-23 expression in the spleen of SFB+ young and middle-aged K/BxN mice ( $n=3$ mice in each group)

involved in inducing GC responses. Because GCs play a key role in the T-cell-dependent $\mathrm{Ab}$ response, we compared the GC responses of SFB- and SFB $+\mathrm{K} / \mathrm{BxN}$ mice in both age groups. Our results showed a greater induction in the GC B cell (defined by $\mathrm{Fas}^{+} \mathrm{PNA}^{+}$) population in the spleen of SFB+ versus $\mathrm{SFB}-$ young controls (Fig. 4b). There was a tremendous increase in the GC B cell population in middle-aged mice regardless of SFB status. These data indicate that a strong Tfh and GC B cell response occurs with age and some specific gut microbiota such as SFB can elevate the young Tfh and $\mathrm{GC}$ immune compartment to mimic the increase in Tfh and $\mathrm{GC}$ response in middle-aged mice.

\section{Tfh cell proliferation and differentiation in young and middle-aged K/BxN mice}

We next asked what contributed to the robust Tfh response in the middle-aged mice. We first examined whether Tfh cells exhibit stronger proliferation with age in both $\mathrm{SFB}+$ and SFB- conditions. To our surprise, there was a decrease in cycling Tfh cells as demonstrated by the lower percentage of $\mathrm{Ki} 67^{+} \mathrm{Tfh}$ cells in middleaged mice regardless of SFB status (Fig. 5a). We then asked whether there was an increase of Tfh cell differentiation with age that caused the increase in the Tfh cell response in middle-aged mice. Bcl-6 is the master transcriptional regulator of Th cells, and promotes 


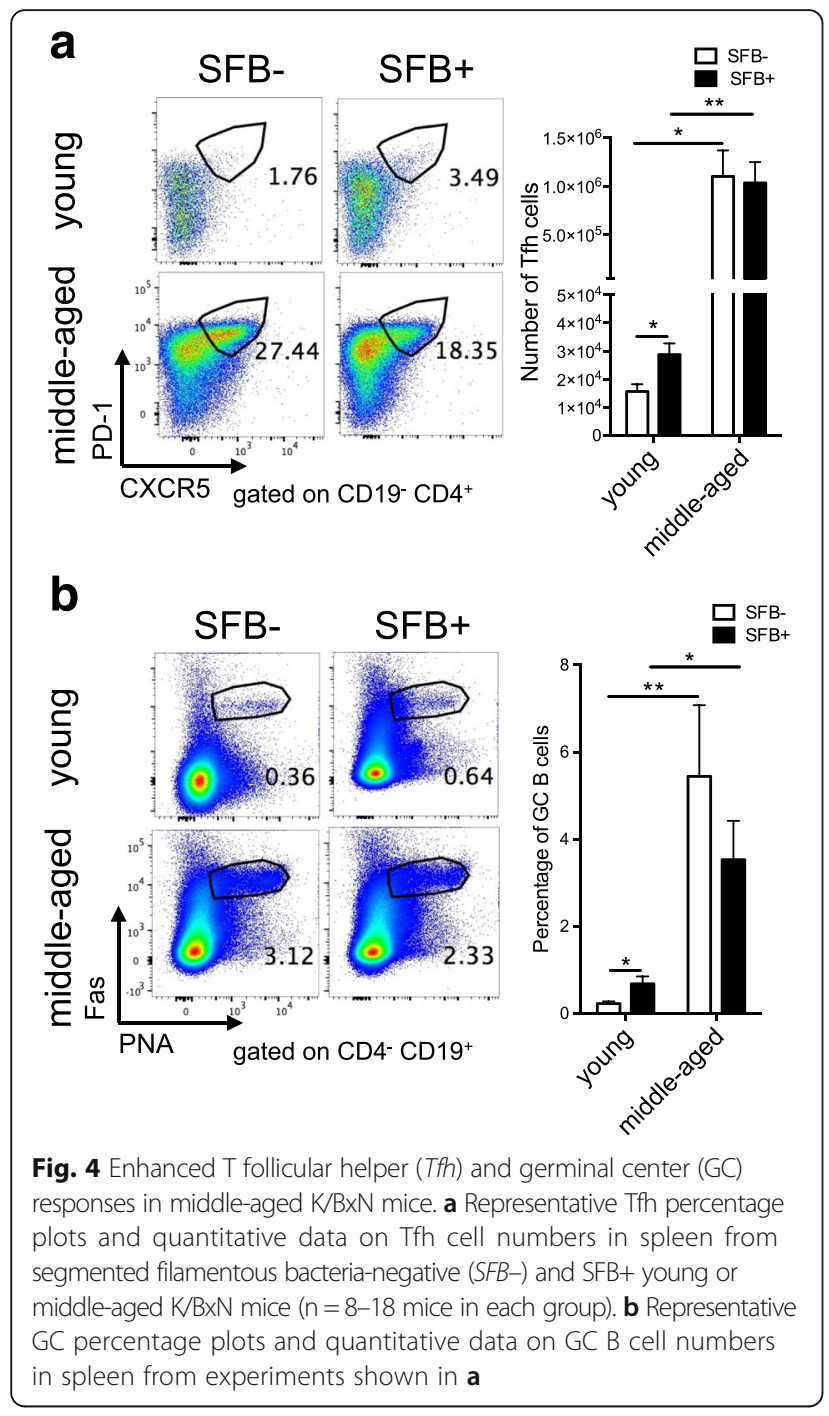

differentiation of non-Tfh $\mathrm{CD} 4^{+} \mathrm{T}$ cells into Tfh cells $[16$, 35 . Thus, we next examined the expression of Bcl- 6 and found that there was a mild but significant drop in Bcl-6 expression in the non-Tfh cells of middle-aged compared to young mice in both the SFB- and SFB+ groups (Fig. 5b). As we have previously demonstrated that SFB specifically induce Tfh differentiation in Peyer's patches (PPs) but not in the spleen of young $\mathrm{K} / \mathrm{BxN}$ mice, we also examined Bcl-6 expression in PPs. Though SFB induced Bcl-6 upregulation in PP non-Tfh cells in the young group, there was a lack of Bcl-6 induction in the non-Tfh cells in the middle-aged group (Fig. 5c). As reported in previous studies $[16,17]$, once differentiated into Tfh cells, Bcl-6 was expressed at a higher level than in non-Tfh cells and there were no differences in $\mathrm{Bcl}-6$ expression between the young and middle-aged groups (Fig. $5 \mathrm{~b}$ and c). These results suggest that the increase in Tfh cell response in middle-aged $\mathrm{K} / \mathrm{BxN}$ mice was not due to enhancement of Tfh cell proliferation or differentiation.

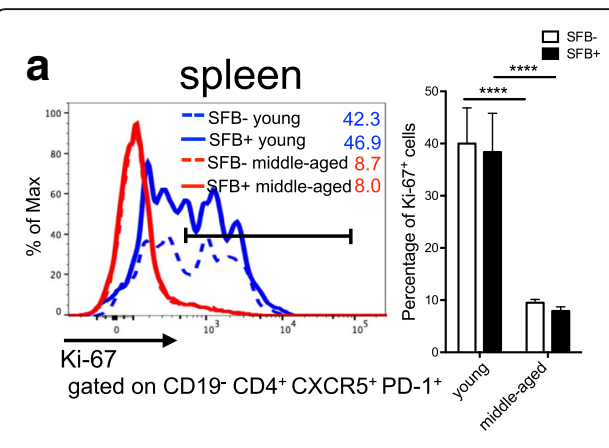

b

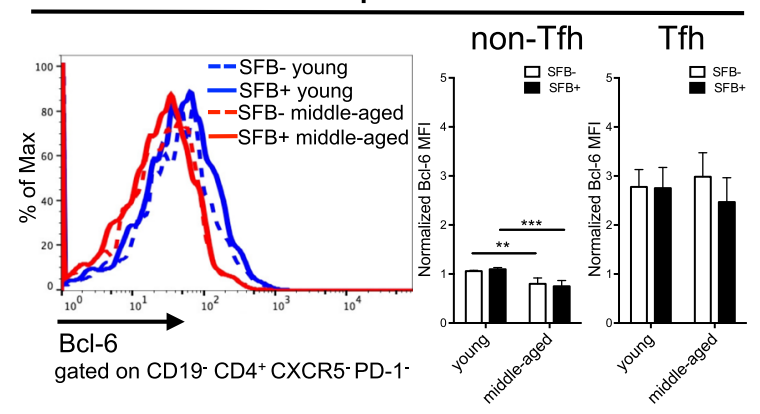

c

\section{PPs}

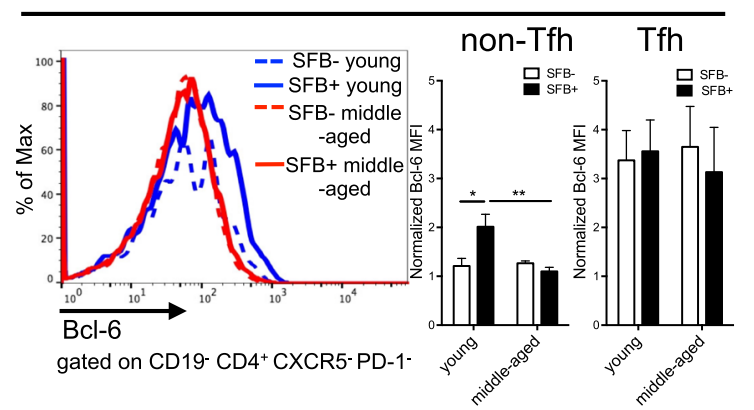

Fig. 5 Reduced $T$ follicular helper (Tfh) proliferation and differentiation in middle-aged K/BxN mice. a Representative histogram overlays and quantitative data on $\mathrm{Ki}-67^{+}$Tfh cells in the spleen from segmented filamentous bacteria-negative (SFB-) and SFB+ of young or middleaged K/BxN mice ( $n=4-14$ mice of each group). $\mathbf{b}, \mathbf{c}$ Representative histogram overlays of $\mathrm{BCl}-6$ expression in non-Tfh cells and quantitative data on normalized Bcl-6 mean fluorescence intensity (MFI) in non-Tfh and Tfh cells from the spleen (b) and Peyer's patches (PPs) (c) from experiments shown in a. Bcl-6 MFI was normalized to splenic non-Tfh cells from one SFB- young mouse within each experiment

\section{Excessive accumulation of effector and effector memory} Tfh cells in middle-aged $\mathrm{K} / \mathrm{BxN}$ mice

Since we did not observe increased Tfh cell proliferation or differentiation in the middle-aged mice, we next addressed whether the soaring Tfh response in middleaged mice was elicited by an accumulation of active and/ or memory Tfh cells. To investigate this, we focused on SFB colonized mice, which display a strong Tfh response in both age groups, and analyzed the surface expression of CD62L and CD44 on Tfh cells. Our results revealed 
an increase in effector and/or effector memory-type $\mathrm{T}$ cells $\left(\mathrm{CD} 62 \mathrm{~L}^{\mathrm{lo}} \mathrm{CD} 44^{\text {hi }}\right)$ but not central memory-type $\mathrm{T}$ cells $\left(\mathrm{CD} 62 \mathrm{~L}^{\mathrm{hi}} \mathrm{CD} 44^{\text {hi }}\right)$ in middle-aged compared to young mice (Fig. 6a). This analysis revealed that the Tfh cells that were elevated with age were of an effector phenotype, which contrasts with non-Tfh cells, where we did not observe a difference in the effector phenotype subpopulations between the young and middleaged groups (Fig. 6b). Thus, the significant increase in Tfh cells in middle-aged mice is contributed by the accumulation of Th cells of an effector phenotype.

\section{Discussion}

Despite progress in understanding loss of immune function in Tfh cells and GC B cells with age, much less is known about age-associated changes in these cell types in an autoimmune setting. We have found that in contrast to Th17 cells, Tfh cells are heavily accumulated in middle-aged autoimmune arthritic mice. Most of the Tfh cells in middle-aged $\mathrm{K} / \mathrm{BxN}$ mice are of the effector phenotype $\left(\mathrm{CD} 62 \mathrm{~L}^{\mathrm{lo}} \mathrm{CD} 44^{\mathrm{hi}}\right)$. However, we believe these CD62L ${ }^{\text {lo }} \mathrm{CD} 44^{\text {hi }}$ Tfh cells are mostly effector memory cells and not effectors. Our rationale is that in contrast to their young counterparts, when middle-aged non-Tfh cells from PPs were exposed to SFB, a potent Tfh stimulus, they were not able to upregulate their Bcl-6 and undergo SFB-induced Tfh differentiation. Therefore, we propose that these middle-aged Tfh cells are generated at a young age while Tfh differentiation is active. They later survive as memory Tfh cells, which can readily become effector Tfh cells upon encountering self-antigen. In support of this hypothesis, we found that middle-aged Tfh cells in $\mathrm{K} / \mathrm{BxN}$ mice are rather quiescent, demonstrated by their lower proliferation phenotype, which potentially helps their long-term survival [36].

The data presented here, together with previous reports, suggest that the Tfh cells accumulated over time are major contributors to autoantibody production and arthritis development in middle-aged $\mathrm{K} / \mathrm{BxN}$ mice. To begin with, the autoantibody level is an important disease index in the $\mathrm{K} / \mathrm{BxN}$ model. We and others have reported that arthritis can be induced simply by passively transferring anti-GPI autoantibodies or serum containing anti-GPI autoantibodies into wild-type mice [37, 38]. Our results also indicate that, compared to young mice, middle-aged mice had higher autoantibody titers, which corresponded with their increased ankle thickness (Fig. 1c). Secondly, our previous data showed that Tfh cells are required for autoantibody production in $\mathrm{K} / \mathrm{BxN}$ mice by demonstrating that mice receiving CXCR5deficient KRN T cells, which have impaired Tfh function, developed far fewer autoantibodies and less severe disease compared to those that received CXCR5-sufficient KRN T cells [12]. Third, a soaring Tfh cell population accompanied by a robust GC B cell response was found in middle-aged mice compared to the young group (Fig. 4a and b), and it has been well-established that active Tfh cells are required to maintain GC B cell populations [16, 17]. Finally, Bcl-6 is expressed at similar levels in Tfh cells in both the young and middle-aged groups (Fig. 5b and c). Because Bcl-6 is the master regulator of Tfh cells and controls the expression and function of many Tfh cell molecules $[16,17,39]$, together with the robust GC B cell response in the middle-aged group, these data suggest that middle-aged Tfh cells are functionally competent. Collectively, these data suggest that the accumulated Tfh cells in middle-aged $\mathrm{K} / \mathrm{BxN}$ mice are key contributors to the robust GC B cell response, which in turn leads to increased autoantibody production and arthritis development in middle-aged mice. It is worth mentioning that research focusing on aging carries unique challenges, mainly attributable to the fact that the time required to age mice makes designing gain-of-function or loss-of-function experiments with

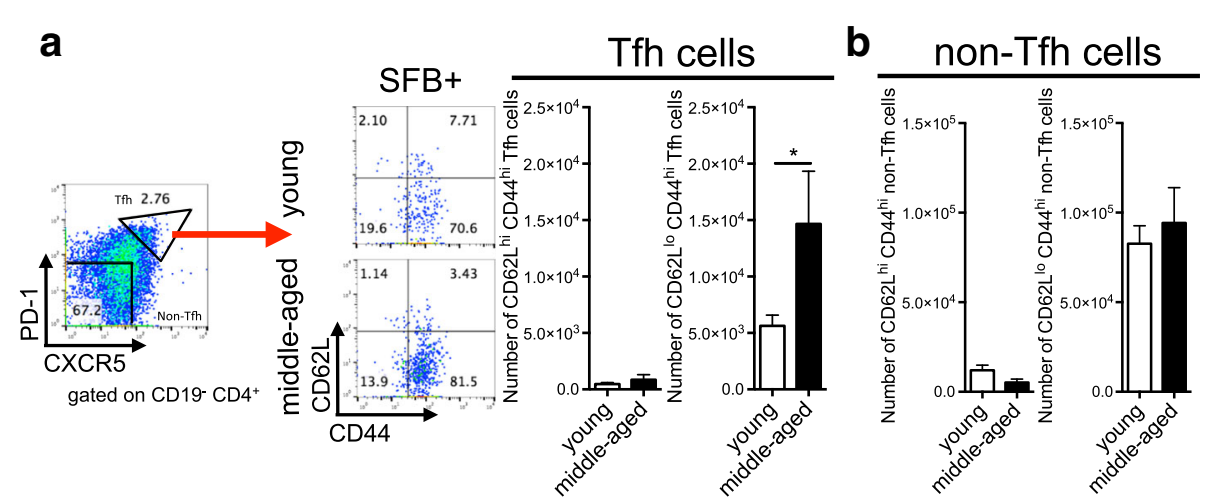

Fig. 6 Accumulated T follicular helper (Tfh) cells of effector phenotype in middle-aged K/BxN mice. a Representative plots and quantitative data on CD62L hi CD44 hi and CD62 L ${ }^{\text {lo } C D 44 ~}{ }^{\text {hi }}$ Tfh cell numbers in pooled spleen and lymph node cells from segmented filamentous bacteria (SFB+) young or middle-aged K/BxN mice ( $n=4-7$ in each group). $\mathbf{b}$ Quantitative data on CD62L ${ }^{\text {hi }} C D 44^{\text {hi }}$ and $C D 62 L^{\text {lo }} C D 44^{\text {hi }}$ non-Tfh cell numbers in pooled spleen and lymph node cells from the experiment shown in $\mathbf{a}$ 
older mice much less feasible than studies involving only young subjects. However, this is an urgent topic that requires intense future focus, as age is a major risk factor for countless diseases, including many autoimmune diseases, and the world's elderly population has been increasing at an unprecedented rate.

Our results thus could help explain the long-standing observation that with age, there is a reduction in $\mathrm{Ab}$ response to infection or vaccination, whereas there is an increase in autoantibody production in autoimmune patients, a phenomenon that might appear to be controversial at first sight [40]. This can be explained by an elegant study showing that despite aging mice displaying an increased Tfh population, the Tfh response to viral infections in aging mice is impaired, which is indicated by a severe reduction in the germinal center $\mathrm{B}$ cell response [41]. This is in sharp contrast to our results, which demonstrate that the increased Tfh population helps B cells to develop a robust GC B cell response in an autoimmune condition. Our results provide a potential mechanism to explain these seemingly paradoxical findings. We propose that during the aging process, there are reduced $\mathrm{T}$ effector cell activities toward new antigens. Indeed, our results show declining differentiation of Th17 and Tfh cells in response to a newly introduced antigen, SFB, in middle-aged mice. However, autoimmune diseases such as RA often have a latent phase [42], during which autoimmune Tfh cells respond to self-antigen from youth while Tfh differentiation is still active, and are accumulated with age. Because of their preferential accumulation and survival advantage over other non-Tfh cells during the aging process (Fig. 6a and b), Tfh cells eventually emerge as a significant cell type involved in the pathogenesis of RA in middle age. Recently, a population of blood circulating Tfh (cTfh) cells has been described as memory Tfh cells [43, 44]. In support of our hypothesis that memory Tfh cells could contribute to autoimmunity in middle-age, a higher frequency of circulating Tfh cells have been detected in patients with RA, and there is a positive correlation of increased cTfh cells with disease activity and autoantibody production [45]. $\mathrm{T}$ follicular regulatory cells (Tfr), serve as important counter-inhibitors that downregulate the Tfh cell response. It has been proposed that an increased ratio of inhibitory Tfr cells in aged mice contributes to defective $\mathrm{Ab}$ production in aging upon antigen immunization [46]. However, in an autoimmune setting in middle-aged mice, we did not observe representation of Tfr cells over and above Tfh cells that could have better countered the accumulated Tfh population (unpublished observations).

It has been demonstrated that there is an increase in $\mathrm{IL}-17^{+} \mathrm{CD} 4^{+} \mathrm{T}$ cells in aging mice and one of the reports further demonstrated that memory Th17 cells are an important source of IL-17 production in aging mice [47, 48]. Our findings suggest that there is an overall reduction in Th17 cells in middle-aged $\mathrm{K} / \mathrm{BxN}$ mice, which also displayed decreased differentiation of IL-17producing cells from naive $\mathrm{CD} 4^{+} \mathrm{T}$ cells compared to the young group. The discrepancy between our results and previous mouse data could be due to the difference between middle-aged mice used in this study compared to aged mice in the former study. The other, more likely reason is the difference between using mice with an autoimmune background $(\mathrm{K} / \mathrm{BxN})$ compared to wildtype mice (B6 and $\mathrm{CBA}$ ) used in the previous study. On that note, it is worth mentioning that similar to our findings, there were two studies in humans reporting a reduction in $\mathrm{IL}-17^{+} \mathrm{CD} 4^{+} \mathrm{T}$ cells in the elderly compared to the young $[49,50]$. As in humans, $\mathrm{CD}^{+} \mathrm{T}$ cells from autoimmune mice such as $\mathrm{K} / \mathrm{BxN}$ mice are more antigen-experienced compared to naïve wild-type mice such as B6 and CBA. It will be interesting to determine whether the antigen experience of $\mathrm{T}$ cells contributes to the differences in IL-17 response between our findings and previous reports.

In humans, initial evidence suggests an important role for IL-17 in the pathogenesis of several inflammatory diseases, including RA [20,51]. However it was later discovered that the increased expression of IL-17 is not restricted to synovial tissue in patients with RA; it is also observed in patients with psoriatic arthritis and inflammatory osteoarthritis. The heterogeneous expression pattern of IL-17 in patients with RA has been proposed to be responsible for the non-responsiveness to anti-IL17 clinical therapy in RA [52]. The $\mathrm{K} / \mathrm{BxN}$ model results further suggest that the problematic maintenance of Th17 cells in middle-aged compared to young individuals may further contribute to the ineffectiveness of anti-IL-17 therapy in patients with RA, who are mostly middle-aged and older individuals. This is supported by a report showing a significant but small number of IL-17 ${ }^{+} \mathrm{CD}^{+} \mathrm{T}$ cells are detected $(0.9-1.2 \%)$ in the synovial fluid and peripheral blood of patients with RA [53]. In this case, anti-IL-17 treatment may function better in younger or pre-clinical subgroups of patients.

Aging-associated alterations in gut microbiota composition have been well-documented $[8,9]$. They are suggested to be caused by an age-related decline in immune function. When we colonized $\mathrm{K} / \mathrm{BxN}$ mice with $\mathrm{SFB}$, we observed that middle-aged $\mathrm{K} / \mathrm{BxN}$ mice displayed a trend toward an increase in susceptibility to SFB colonization compared to their young counterparts. Normal gut IgA is a key immune player in reducing SFB colonization [54]. It is possible that the defect in SFBinduced Tfh differentiation in PPs indicated by the lack of SFB-mediated Bcl-6 induction in middle-aged mice could lead to reduced production of SFB-specific IgA, 
which results in an expansion of SFB in the gut. However, it appears that $\mathrm{T}$ cells in the middle-aged are less capable of responding to SFB, which can be seen at a molecular level, compared to young T cells. For example, in young $\mathrm{K} / \mathrm{BxN}$ mice, we have previously reported that SFB promote non-Tfh cells differentiating into Tfh cells in PPs by upregulating Bcl-6 expression in non-Tfh cells in PPs [12]. On the other hand, SFB colonization does not upregulate Bcl-6 expression in non-Tfh cells in PPs in middle-aged $\mathrm{K} / \mathrm{BxN}$ mice.

A strong Tfh response can still be observed in SFBmiddle-aged $\mathrm{K} / \mathrm{BxN}$ mice, suggesting that commensals other than SFB may substitute for SFB in promoting the Tfh response during the aging process, which results in a strong accumulation of Tfh cells despite the lack of SFB. In contrast, SFB is more specifically required for Th17 than Tfh responses, which is supported by data from Littman's group [27]. Middle-aged $\mathrm{K} / \mathrm{BxN}$ mice display reduced but still significant SFB-mediated Th17 induction in the lung (but not in the spleen or SI-LP), further supporting SFB-specific Th17 induction. We have previously reported that Tfh and Th17 cells can both contribute to autoantibody and arthritis development in young $\mathrm{K} / \mathrm{BxN}$ mice [12]. Thus, our data from middle-aged $\mathrm{K} / \mathrm{BxN}$ mice suggest that the enormous amount of Tfh cells in the middle-aged group is sufficient to induce a robust GC B cell response that promotes severe arthritis with less help from Th17 cells. The reduced but still significant induction of Th17 cells (at least in the lung) in SFB colonized mice may partly contribute to the higher anti-GPI titer in SFB+ middleaged $\mathrm{K} / \mathrm{BxN}$ mice. Although this did not contribute to visible pathological differences in the mice, which could be due to the limitations of detection of disease symptoms and severity in mice, the differential auto-Ab titer may still contribute to different degrees of disease manifestation among patients. Using TCR Tg $\mathrm{K} / \mathrm{BxN}$ mice in our study allowed us to significantly control the TCR repertoire over the aging process. However, it is a wellrecognized phenomenon that incomplete allelic exclusion of TCRs can lead to dual TCR expression on T cells, not only in TCR Tg mice, but also in wild-type mice and humans $[55,56]$. Furthermore, dual TCR expression has been reported to increase with aging [22]. Thus, it will be very interesting to determine whether microbiota contribute to dual TCR expression during the aging process, and how this may impact autoimmune development.

Our data also suggest that certain microbiota, such as $\mathrm{SFB}$, may render young hosts prone to an overactive immune phenotype, as evidenced by the young $\mathrm{K} / \mathrm{BxN}$ mice colonized with SFB displaying stronger disease and immune phenotypes, such as increased Tfh and GC responses, that are reminiscent of, though still much lower than, those in middle-aged mice. Interestingly, patients with RA have a phenotype of premature immune aging (immunosenescence) including telomere shortening and contraction of the T cell repertoire [57]. Further investigation is required to determine whether immunosenescence in RA could be contributed to by the human equivalent of microbiota species similar to mouse SFB, with strong host immunomodulation effects.

\section{Conclusions}

The $\mathrm{K} / \mathrm{BxN}$ mice allow us to systemically examine the age-associated and gut microbiota- associated impact on pathological $\mathrm{T}$ effector cells, Tfh and Th17 cells, in the development of autoantibody-mediated autoimmune arthritis. Our results show that despite both Tfh and Th17 cells having been reported to participate in the pathogenesis of autoimmune arthritis, there is a clear age-associated accumulation of Tfh but not Th17 cells in the middle-aged group compared to their young counterparts. SFB colonization, a potent stimulus for inducing Tfh differentiation, fails to promote Tfh differentiation in the middle-aged group, which suggests that most of the middle-aged Tfh cells with an effector phenotype $\left(\mathrm{CD} 62 \mathrm{~L}^{\mathrm{lo}} \mathrm{CD} 44^{\mathrm{hi}}\right)$ are Tfh effector memory cells induced at an earlier age. Our results also indicate that exposure to certain benign commensals may cause the young host to display an overactive immune system similar to the middle-aged group. Targeting the survival of Tfh cells and colonization of immunomodulatory commensals may offer immune-based and/or microbebased therapies in RA.

\section{Abbreviations \\ Ab: Antibody; Ag: Antigen; B6: C57BL/6; cTfh: Circulating T follicular helper; DMEM: Dulbecco's modified Eagle's medium; \\ EDTA: Ethylenediaminetetraacetic acid; ELISA: Enzyme-linked immunosorbent assay; FBS: Fetal bovine serum; FCS: Fetal calf serum; FITC: Fluorescein isothiocyanate; GC: Germinal center; GPI: Glucose-6-phosphate isomerase: H\&E: Hematoxylin and eosin; iBALT: Inducible bronchus-associated lymphoid tissue; IL-17A/IL-17: Interleukin-17A; K/BxN: F1 mice of KRN/B6 x NOD; mAbs: Monoclonal antibodies; MFI: Mean fluorescence intensity; PBS: Phosphate-buffered saline; PNA: Peanut agglutinin; PPs: Peyer's patches; RA: Rheumatoid arthritis; SFB: Segmented filamentous bacteria; SI-LP: Small intestine-lamina propria; TCR: T cell receptor; Tfh: T follicular helper; Tfr: T follicular regulatory cells; Tg: Transgenic; TGF: Transforming growth factor; Th17: T helper 17}

\section{Acknowledgements}

Not applicable.

\section{Funding}

This work was supported by grants from the NIH (R56Al107117 and R01Al107117) and by the Southwest Clinic and Research Institute Fund to HW.

\section{Availability of data and materials}

The datasets used and/or analyzed during the current study are available from the corresponding author on reasonable request. 


\section{Authors' contributions}

FT and HW designed the project. FT, KF, and PB performed experiments and data analysis. DN, HM, and WR performed sample collections and ankle measurements in mouse model studies. FT, KF, and HW participated in the interpretation of data, and drafted and revised the manuscript. All authors read and approved the final manuscript.

\section{Ethics approval}

All experiments were conducted according to the guidelines of the Institutional Animal Care and Use Committee at the University of Arizona under the protocol reference number $11-278$

\section{Consent for publication}

Not applicable.

\section{Competing interests}

The authors declare that they have no competing interests.

\section{Publisher's Note}

Springer Nature remains neutral with regard to jurisdictional claims in published maps and institutional affiliations.

Received: 10 March 2017 Accepted: 27 July 2017

Published online: 15 August 2017

\section{References}

1. Dorshkind K, Montecino-Rodriguez E, Signer RA. The ageing immune system: is it ever too old to become young again? Nat Rev Immunol. 2009; 9(1):57-62.

2. Rosato E, Salsano F. Immunity, autoimmunity and autoimmune diseases in older people. J Biol Regul Homeost Agents. 2008;22(4):217-24.

3. Goronzy JJ, Weyand CM. T cell homeostasis and autoreactivity in rheumatoid arthritis. Curr Dir Autoimmun. 2001;3:112-32.

4. Kamada N, Seo SU, Chen GY, Nunez G. Role of the gut microbiota in immunity and inflammatory disease. Nat Rev Immunol. 2013;13(5):321-35.

5. Sekirov I, Russell SL, Antunes LC, Finlay BB. Gut microbiota in health and disease. Physiol Rev. 2010;90(3):859-904.

6. Hooper LV, Littman DR, Macpherson AJ. Interactions between the microbiota and the immune system. Science. 2012;336(6086):1268-73.

7. Wu HJ, Wu E. The role of gut microbiota in immune homeostasis and autoimmunity. Gut Microbes. 2012;3(1):4-14.

8. Claesson MJ, Jeffery IB, Conde S, Power SE, O'Connor EM, Cusack S, et al. Gut microbiota composition correlates with diet and health in the elderly. Nature. 2012;488(7410):178-84.

9. Claesson MJ, Cusack S, O'Sullivan O, Greene-Diniz R, de Weerd H, Flannery E, et al. Composition, variability, and temporal stability of the intestinal microbiota of the elderly. Proc Natl Acad Sci U S A. 2011;108 Suppl 1:4586-91.

10. Scher JU, Sczesnak A, Longman RS, Segata N, Ubeda C, Bielski C, et al. Expansion of intestinal Prevotella copri correlates with enhanced susceptibility to arthritis. elife. 2013;2:e01202.

11. Wu HJ, Ivanov II, Darce J, Hattori K, Shima T, Umesaki Y, et al. Gut-residing segmented filamentous bacteria drive autoimmune arthritis via T helper 17 cells. Immunity. 2010;32(6):815-27.

12. Teng F, Klinger CN, Felix KM, Bradley CP, Wu E, Tran NL, et al. Gut microbiota drive autoimmune arthritis by promoting differentiation and migration of Peyer's patch T follicular helper cells. Immunity. 2016;44(4):875-88.

13. Viladomiu M, Kivolowitz C, Abdulhamid A, Dogan B, Victorio D, Castellanos JG, et al. IgA-coated E. coli enriched in Crohn's disease spondyloarthritis promote TH17-dependent inflammation. Sci Transl Med. 2017;9(376): eaaf9655.

14. Suurmond J, Diamond B. Autoantibodies in systemic autoimmune diseases: specificity and pathogenicity. J Clin Investig. 2015;125(6):2194-202.

15. Browning JL. B cells move to centre stage: novel opportunities for autoimmune disease treatment. Nat Rev Drug Discov. 2006;5(7):564-76.

16. Crotty S. Follicular helper CD4 T cells (TFH). Annu Rev Immunol. 2011;29: 621-63

17. Crotty S. T follicular helper cell differentiation, function, and roles in disease. Immunity. 2014;41(4):529-42.

18. Ma CS, Deenick EK, Batten M, Tangye SG. The origins, function, and regulation of T follicular helper cells. J Exp Med. 2012;209(7):1241-53.
19. Ueno H, Banchereau J, Vinuesa CG. Pathophysiology of T follicular helper cells in humans and mice. Nat Immunol. 2015;16(2):142-52.

20. Korn T, Bettelli E, Oukka M, Kuchroo VK. IL-17 and Th17 cells. Annu Rev Immunol. 2009:27:485-517.

21. Monach PA, Mathis D, Benoist C. The K/BxN arthritis model. Current protocols in immunology. 2008:Chapter 15:Unit 1522.

22. Linton PJ, Haynes L, Klinman NR, Swain SL. Antigen-independent changes in naive CD4 T cells with aging. J Exp Med. 1996;184(5):1891-900.

23. Ivanov II, Atarashi K, Manel N, Brodie EL, Shima T, Karaoz U, et al. Induction of intestinal Th17 cells by segmented filamentous bacteria. Cell. 2009;139(3):485-98.

24. Round JL, Lee SM, Li J, Tran G, Jabri B, Chatila TA, et al. The Toll-like receptor 2 pathway establishes colonization by a commensal of the human microbiota. Science. 2011;332(6032):974-7.

25. Atarashi $K$, Tanoue $T$, Shima $T$, Imaoka A, Kuwahara $T$, Momose $Y$, et al. Induction of colonic regulatory $T$ cells by indigenous Clostridium species. Science. 2011:331(6015):337-41.

26. Hill DA, Artis D. Intestinal bacteria and the regulation of immune cell homeostasis. Annu Rev Immunol. 2010;28:623-67.

27. Yang $Y$, Torchinsky MB, Gobert $M$, Xiong H, Xu M, Linehan JL, et al. Focused specificity of intestinal TH17 cells towards commensal bacterial antigens. Nature. 2014;510(7503):152-6.

28. Rangel-Moreno J, Hartson L, Navarro C, Gaxiola M, Selman M, Randall TD. Inducible bronchus-associated lymphoid tissue (BALT) in patients with pulmonary complications of rheumatoid arthritis. J Clin Investig. 2006;116(12):3183-94

29. Shilling RA, Williams JW, Perera J, Berry E, Wu Q, Cummings OW, et al. Autoreactive $T$ and $B$ cells induce the development of bronchus-associated lymphoid tissue in the lung. Am J Respir Cell Mol Biol. 2013;48(4):406-14.

30. Naskar D, Teng F, Felix KM, Bradley CP, Wu HJ. Synthetic retinoid AM80 ameliorates lung and arthritic autoimmune responses by inhibiting $T$ follicular helper and Th17 cell responses. J Immunol. 2017;198(5):1855-64.

31. Ivanov II, Frutos Rde L, Manel N, Yoshinaga K, Rifkin DB, Sartor RB, et al. Specific microbiota direct the differentiation of IL-17-producing T-helper cells in the mucosa of the small intestine. Cell Host Microbe. 2008;4(4):337-49.

32. Tan TG, Sefik E, Geva-Zatorsky N, Kua L, Naskar D, Teng F, et al. Identifying species of symbiont bacteria from the human gut that, alone, can induce intestinal Th17 cells in mice. Proc Natl Acad Sci U S A. 2016:113(50):E8141-E50.

33. Stritesky GL, Yeh N, Kaplan MH. IL-23 promotes maintenance but not commitment to the Th17 lineage. J Immunol. 2008;181(9):5948-55.

34. Huang $\mathrm{H}$, Benoist $\mathrm{C}$, Mathis D. Rituximab specifically depletes short-lived autoreactive plasma cells in a mouse model of inflammatory arthritis. Proc Natl Acad Sci U S A. 2010;107(10):4658-63.

35. Vinuesa CG, Linterman MA, Yu D, MacLennan IC. Follicular helper T cells. Annu Rev Immunol. 2016:34:335-68.

36. Hua X, Thompson CB. Quiescent T cells: actively maintaining inactivity. Nat Immunol. 2001:2(12):1097-8.

37. Wu HJ, Sawaya H, Binstadt B, Brickelmaier M, Blasius A, Gorelik L, et al. Inflammatory arthritis can be reined in by CpG-induced DC-NK cell cross talk. J Exp Med. 2007;204(8):1911-22.

38. Maccioni M, Zeder-Lutz G, Huang H, Ebel C, Gerber P, Hergueux J, et al. Arthritogenic monoclonal antibodies from K/BxN mice. J Exp Med. 2002; 195(8):1071-7.

39. Hatzi K, Nance JP, Kroenke MA, Bothwell M, Haddad EK, Melnick A, et al. $\mathrm{BCL} 6$ orchestrates Tfh cell differentiation via multiple distinct mechanisms. J Exp Med. 2015;212(4):539-53.

40. Linterman MA. How T, follicular helper cells and the germinal centre response change with age. Immunol Cell Biol. 2014;92(1):72-9.

41. Lefebvre JS, Masters AR, Hopkins JW, Haynes L. Age-related impairment of humoral response to influenza is associated with changes in antigen specific T follicular helper cell responses. Sci Rep. 2016;6:25051.

42. Goodnow CC. Multistep pathogenesis of autoimmune disease. Cell. 2007; 130(1):25-35.

43. Locci M, Havenar-Daughton C, Landais E, Wu J, Kroenke MA, Arlehamn CL, et al. Human circulating PD-1 + CXCR3-CXCR5+ memory Tfh cells are highly functional and correlate with broadly neutralizing HIV antibody responses. Immunity. 2013;39(4):758-69.

44. Morita R, Schmitt N, Bentebibel SE, Ranganathan R, Bourdery L, Zurawski G, et al. Human blood CXCR5(+)CD4(+) T cells are counterparts of T follicular cells and contain specific subsets that differentially support antibody secretion. Immunity. 2011;34(1):108-21. 
45. Liu R, Wu Q, Su D, Che N, Chen H, Geng L, et al. A regulatory effect of IL-21 on T follicular helper-like cell and B cell in rheumatoid arthritis. Arthritis Res Ther. 2012;14(6):R255.

46. Sage PT, Tan CL, Freeman GJ, Haigis M, Sharpe AH. Defective TFH cell function and increased TFR cells contribute to defective antibody production in aging. Cell Rep. 2015;12(2):163-71.

47. Ouyang X, Yang Z, Zhang R, Arnaboldi P, Lu G, Li Q, et al. Potentiation of Th17 cytokines in aging process contributes to the development of colitis. Cell Immunol. 2011;266(2):208-17.

48. Huang MC, Liao JJ, Bonasera S, Longo DL, Goetzl EJ. Nuclear factor-kappaBdependent reversal of aging-induced alterations in T cell cytokines. FASEB J. 2008;22(7):2142-50.

49. Lee JS, Lee WW, Kim SH, Kang Y, Lee N, Shin MS, et al. Age-associated alteration in naive and memory Th17 cell response in humans. Clin Immunol. 2011;140(1):84-91.

50. Zhou M, Zou R, Gan H, Liang Z, Li F, Lin T, et al. The effect of aging on the frequency, phenotype and cytokine production of human blood CD4 + CXCR5 + T follicular helper cells: comparison of aged and young subjects. Immun Ageing. 2014;11:12

51. Gabay C, Krenn V, Bosshard C, Seemayer CA, Chizzolini C, Huard B. Synovial tissues concentrate secreted APRIL. Arthritis Res Ther. 2009;11(5):R144.

52. van Baarsen $L G$, Lebre MC, van der Coelen D, Aarrass S, Tang MW Ramwadhdoebe $\mathrm{TH}$, et al. Heterogeneous expression pattern of interleukin 17A (IL-17A), L-17 F and their receptors in synovium of rheumatoid arthritis, psoriatic arthritis and osteoarthritis: possible explanation for nonresponse to anti-lL-17 therapy? Arthritis Res Ther. 2014;16(4):426.

53. Zizzo G, De Santis M, Bosello SL, Fedele AL, Peluso G, Gremese E, et al. Synovial fluid-derived Thelper 17 cells correlate with inflammatory activity in arthritis, irrespectively of diagnosis. Clin Immunol. 2011;138(1):107-16.

54. Suzuki K, Meek B, Doi Y, Muramatsu M, Chiba T, Honjo T, et al. Aberrant expansion of segmented filamentous bacteria in IgA-deficient gut. Proc Nat Acad Sci U S A. 2004;101(7):1981-6.

55. Heath WR, Carbone FR, Bertolino P. Kelly J, Cose S, Miller JF. Expression of two T cell receptor alpha chains on the surface of normal murine T cells. Eur J Immunol. 1995;25(10):1617-23.

56. Padovan E, Casorati G, Dellabona P, Meyer S, Brockhaus M, Lanzavecchia A. Expression of two T cell receptor alpha chains: dual receptor T cells. Science. 1993;262(5132):422-4.

57. Weyand CM, Yang Z, Goronzy JJ. T-cell aging in rheumatoid arthritis. Curr Opin Rheumatol. 2014;26(1):93-100.

\section{Submit your next manuscript to BioMed Central and we will help you at every step:}

- We accept pre-submission inquiries

- Our selector tool helps you to find the most relevant journal

- We provide round the clock customer support

- Convenient online submission

- Thorough peer review

- Inclusion in PubMed and all major indexing services

- Maximum visibility for your research

Submit your manuscript at www biomedcentral.com/submit

) Biomed Central 